\title{
PROMOÇÃO DE SAÚdE BUCAL PARA PESSOAS PORTADORAS DE PARALISIA CEREBRAL
}

Gabriel Marques de Souza, Andreia Heloisa Muza da Silva, Alexandre Tomiazzi Gualberto Chagas, Juliane Avansini Marsicano, Rosana Leal do Prado.

Universidade do Oeste Paulista - UNOESTE, Faculdade de Odontologia. E-mail: rosanahb@yahoo.com.br

\section{RESUMO}

O objetivo deste estudo foi verificar a efetividade de orientações em saúde bucal para portadores de paralisia cerebral e seus cuidadores. Foram avaliadas em dois momentos a condição de saúde bucal de sete pessoas com paralisia cerebral (PC) e práticas de seus cuidadores quanto a cuidados de higiene bucal. Utilizou-se um roteiro semiestruturado, identificando variáveis como: gênero, renda, idade, moradia, dentre outras do indivíduo com PC. Em seguida avaliou-se a condição bucal dos voluntários com PC por meio dos índices de cárie dentária (CPOD) e índice de higiene oral simplificado (IHOS). Em relação ao IHOS, durante a primeira e segunda avaliação observou-se melhora nos índices. Porém, a análise do IHOS dos pacientes nos dois períodos avaliados, não apresentou significância estatística $(p=0,1003$ ). No estudo foi observado que apesar de haver efetividade nas orientações realizadas para os portadores de paralisia cerebral e seus cuidadores, não foi observada diferença estatística significante.

Palavras-chave: Paralisia Cerebral, Saúde Bucal, Educação em Saúde, Promoção da Saúde

\section{ORAL HEALTH PROMOTION FOR PEOPLE WITH CEREBRAL PALSY}

\begin{abstract}
The aim of this study was to verify the effectiveness of oral health guidelines for patients with cerebral palsy and their caregivers. The oral health condition of seven people with cerebral palsy (CP) and their caregivers' practices regarding oral hygiene care were evaluated in two moments. A semi-structured script was used, identifying variables such as gender, income, age, housing, among others of the individual with $\mathrm{CP}$. Then, the oral condition of the volunteers with $\mathrm{CP}$ was evaluated by means of the dental caries indexes (DMFT) and the simplified oral hygiene index (OHIS). Regarding the OHIS, during the first and second evaluation it was observed an improvement in the indices. However, the IHOS analysis of the patients in both periods was not statistically significant $(p=0.1003)$. In the study, it was observed that, despite the effectiveness of the guidelines for the patients with cerebral palsy and their caregivers, no significant statistical difference was observed.
\end{abstract}

Keywords: Cerebral palsy, Oral health, Health Education, Health Promotion 


\section{INTRODUÇÃO}

Ações de prevenção em saúde bucal direcionadas para pacientes especiais são de extrema importância, uma vez que pacientes com deficiências podem apresentar déficit intelectual ou motor, o que pode resultar na incapacidade de higienização correta ou na dependência de um cuidador ${ }^{1}$.

Dentre as deficiências encontra-se a paralisia cerebral que pode ser classificada de acordo com a fase em que se desenvolve (pré-natal, perinatal ou pós-natal), ou de acordo com os fatores etiopatogênicos envolvidos (genética, hematológicas, imunológicas, infecciosas, metabólicas, bioquímicas, e os fatores de maturação cerebral ${ }^{2}$.A paralisia cerebral (PC), é descrita como sendo grupo de desordens permanentes de movimentos e postura, causando limitações de atividades, as quais são atribuídas a condições não progressivas que ocorrem no cérebro em desenvolvimento ${ }^{2}$.

As desordens motoras da PC geralmente são acompanhadas por distúrbios sensoriais, percepção, cognição, comunicação, comportamento, epilepsia, e por problemas músculo esqueléticos secundários ${ }^{3}$.

Em relação aos distúrbios motores em pessoas portadoras da PC, há algumas alterações que podem estar relacionadas à forma, função e estética do sistema estomatognático. Alguns exemplos são bruxismo, xerostomia, distúrbios das vias aéreas superiores, respiração bucal e refluxo gastresofágico. A presença do biofilme dentário, gengivite, e o desenvolvimento da cárie dentária, são resultados da incapacidade do indivíduo portador da PC de exercer a sua própria higienização bucal, e por muitas vezes a falta de informação aos responsáveis e o grau de dificuldade para higienizar o indivíduo leva ao descaso desta situação e o agravamento de doenças periodontais ${ }^{4}$. 0 desenvolvimento da doença periodontal é facilitado uma vez que um indivíduo portador de PC vivencia uma dieta de consistência pastosa, que permanece maior tempo na cavidade bucal diminuindo o fluxo salivar, rica em carboidrato, junto com o alto uso de medicamentos, que os tornam ainda mais vulneráveis ${ }^{2,4}$.

Há também mais alguns fatores que podem agravar essa situação, como os fatores socioeconômicos, baixa renda familiar, baixa escolaridade, dependência do paciente nas atividades de vida diária (AVD), falta de serviços odontológicos básicos na rede pública e privada ${ }^{5}$. Portanto a prevenção e o cuidado com estes pacientes devem ser rotineira e eficiente, criando medidas como programas educativos e preventivos capazes de tornar consciente a importância da higienização aos cuidadores e família, estimulando o trabalho em conjunto ${ }^{6}$.

No território Brasileiro o estudo da incidência de pessoas com paralisia cerebral é escasso. Estima-se nos países em desenvolvimento a prevalência de PC é de 7 para 1000 nascidos vivos. Já em países desenvolvidos encontram-se em uma média de 1,5 a 5,9 para 1000 nascidos vivos. O que pode explicar essa diferença entre os países em desenvolvimento e os países desenvolvidos, são as condições de tratamento pré-natal e os cuidados primários a gestante ${ }^{7}$.

A situação atual da saúde bucal de pessoas especiais é precária e pouco estudada. Neste caso a implantação de programas educativos e preventivos é um meio de conhecer, educar, agir e intervir na saúde e na vida dos mesmos, implantando a integração do profissional-pacientes especiais-pais ${ }^{1}$. A falta de vivência e recursos é enorme, dificultando um trabalho preventivo, cirúrgico-restaurador-reabilitador, que na ausência de recursos financeiros contribuem para soluções extremas, como exodontia múltipla ${ }^{1}$.

Outras razões que dificultam a atenção odontológica para pacientes especiais é a escassez desta área no currículo de graduação, falta de conhecimento e de preparo dos profissionais para essa finalidade, falta de cuidado e preparo do tratamento odontológico pelos serviços de saúde e o descaso da saúde bucal pelos cuidadores responsáveis ${ }^{8}$. Segundo Tessier et al. $^{9}$, a família precisa possuir um cuidado centrado ao portador da PC, reconhecendo sua importância, colocando em foco as decisões compartilhadas, dividindo informações, e capacitando-se permanentemente, tomando os cuidados necessários nas decisões e coordenações 
familiares a fim de melhorar a qualidade de vida do portador da PC e todos os membros da família ${ }^{9}$.

O índice de cárie e a quantidade de placa bacteriana são maiores nos pacientes especiais que na média da população ${ }^{1}$.Segundo Lemos e Katz ${ }^{10}$, isso ocorre devido às movimentações não coordenadas da musculatura facial nesses indivíduos, o que pode acarretar uma retenção de alimentos na cavidade bucal, comprometendo a função de autolimpeza ${ }^{10}$.

A cooperação do paciente é primordial para o sucesso do trabalho odontológico. Quando a comunicação é interrompida pela severidade da deficiência do paciente, física, mental ou psicológica, o meio de conseguir realizar a operação do tratamento é sob anestesia geral, que quando indicada corretamente resulta em fins satisfatórios ${ }^{8}$. O cuidado oral prestado a pessoas com paralisia cerebral exige que o profissional adapte suas habilidades frequentes no dia-a-dia viabilizando um tratamento satisfatório e de sucesso. Na maioria dos casos de pacientes com formas leves e moderadas de PC, o tratamento odontológico pode ser executado e tratado com sucesso na pratica clínica ${ }^{11-13 .}$

É importante ressaltar que cuidados em saúde para pacientes especiais requerem estudos específicos, cuidados e atenção dobrados, medidas apropriadas e direcionadas a cada caso, além das que são consideradas como de rotina ${ }^{14,15}$.

Dessa maneira, considerando a escassez de estudos na área e a baixa oferta de formação para o cuidado desses pacientes, este estudo tem sua relevância potencializada.

Com isso, o objetivo deste estudo foi verificar a efetividade de orientações em saúde bucal para portadores de paralisia cerebral e seus cuidadores.

\section{METODOLOGIA}

O estudo de intervenção em cuidados clínicos, de abordagem quantitativa tem como referência a pesquisa-ação, que por sua vez pode ser aplicada em diversas situações como: educação, serviço social, organização, etc. Esse tipo de pesquisa tem como objetivo um envolvimento maior com o trabalho que foi realizado, visando uma compreensão e interação entre pesquisadores e membros. Das situações investigadas, também supõe uma forma de ação planejada de caráter social, educacional e profissional ${ }^{16}$.

Um dos principais objetivos da pesquisa-ação é proporcionar aos pesquisadores e participantes informações para que se tornem capazes de responder com mais clareza a situação em que vivem ${ }^{17}$.

No ciclo seguido pela pesquisa, ocorreram aprimoramentos da prática pela oscilação sistemática entre o agir no campo da prática e investigação a respeito dela. Seguindo esse ciclo, foi planejado, implementado, descrito e avaliado mudanças para melhorar a qualidade de vida do indivíduo, verificando e aprendendo mais conforme ocorria o processo, tanto no ato da prática quanto da própria investigação ${ }^{17,18}$.

Os indivíduos convidados para participar da pesquisa só foram inseridos no projeto mediante a assinatura do consentimento livre e esclarecido, pelo responsável devido à redução da autonomia do portador de paralisia cerebral. O participante tinha o direito de retirar o consentimento a qualquer momento, sem qualquer prejuízo a este (CAAE: 57477216.8.0000.5515).

A pesquisa foi realizada no Curso de graduação em Odontologia da Universidade do Oeste Paulista, município de Presidente Prudente, nas disciplinas de Paciente Especiais I e II, após busca ativa e identificação dos participantes. Foram identificados de 07 pacientes, não havendo restrição relacionada à idade.

No estudo foram realizadas duas abordagens com cada paciente. Na primeira abordagem, em conversa com o cuidador, utilizou-se um roteiro semiestruturado identificando variáveis como: gênero, renda, idade, moradia, grau de escolaridade do cuidador, hábitos de higiene e alimentares 
do indivíduo com PC. Em seguida, os pacientes com PC foram submetidos a uma avaliação de sua condição bucal por meio do índice de dentes cariados, perdidos e obturados (CPOD) e índice de higiene oral simplificada (IHOS).

Ainda na primeira avaliação, foram feitas orientações relacionadas à promoção e prevenção em saúde bucal com o objetivo da melhora da condição bucal dos portadores da PC.

Com base no questionário apresentado e na avaliação clínica, foram abordados os principais problemas bucais encontrados e iniciou-se um planejamento visando melhorar a qualidade bucal do indivíduo portador da PC. Na segunda abordagem, após 60 dias em relação à primeira, foi realizada uma reavaliação, buscando identificar se com as intervenções clínicas e orientação dispensada, ocorreu melhora na condição de saúde bucal do indivíduo portador da PC.

Para registro das condições bucais foram utilizados os índices de dentes cariados perdidos e restaurados (CPOD) e índice de higiene oral simplificado (IHOS). O primeiro, preconizado pela Organização Mundial da Saúde (OMS) permite avaliar, medir e comparar a experiência de cárie dentária em populações. É destinado a avaliação rápida e prática das condições epidemiológicas que apresentam as populações ${ }^{19}$.

O IHOS é considerado simplificado pois avalia somente as superfícies vestibular e lingual dos dentes, representando assim todos os segmentos posteriores e anteriores da cavidade bucal. Para a obtenção do escore referente a cada indivíduo, é realizado cálculo com base em critérios quantitativos, que podem variar de 0 a 3 . Nele, a soma de quantidade de placa por superfície de dentes é exatamente dividida pelo número de superfícies examinadas. Ao final, o escore obtido pode ser classificado em: bom $(0,0-0,6)$, regular $(0,7-1,8)$ e fraco $(1,9-3,0)^{20}$.

Os dados obtidos foram submetidos a uma análise descritiva, e estão apresentados nos resultados. Para a comparação do IHOS nos dois períodos, foi utilizado o teste de Wilcoxon pareado com nível de significância de 5\%. As análises foram realizadas com o software $R$.

\section{RESULTADOS}

Aceitaram participar e foram acompanhados durante a pesquisa, 7 voluntários portadores de paralisia cerebral e seus respectivos cuidadores. Sem exceção, os cuidadores eram do gênero feminino, sendo que seis destes eram mães dos voluntários, e uma, madrasta. Considerando a idade, a maior parte dos voluntários encontra-se no período da adolescência (tabela 1).

Tabela 1. Distribuição percentual dos voluntários com PC, segundo faixa etária, Presidente Prudente -2017

\begin{tabular}{lll}
\hline Faixa Etária & $\mathbf{N}$ & $\mathbf{\%}$ \\
\hline 10-19 anos & 5 & $\mathbf{7 1 , 4}$ \\
20-40 anos & 1 & 14,3 \\
Acima de 40 anos & 1 & 14,3 \\
\hline Total & $\mathbf{7}$ & $\mathbf{1 0 0 , 0}$ \\
\hline
\end{tabular}

Não houve entre os voluntários, discrepância socioeconômica, sendo a renda familiar média $\mathrm{R} \$ 1740,00$. A grande maioria das famílias declarou receber algum auxílio financeiro (tabela 2). 
Tabela 2. Distribuição percentual das famílias dos voluntários, de acordo com tipo de auxílio financeiro recebido, Presidente Prudente - 2017

\begin{tabular}{lll}
\hline Variável & $\mathbf{N}$ & $\mathbf{\%}$ \\
\hline Auxílio Financeiro & & \\
Sim & 5 & 71,4 \\
Não & 2 & 28,6 \\
\hline Total & 7 & 100,0 \\
\hline Tipo de auxílio & & \\
\hline Municipal & 1 & 14,3 \\
Estadual & 1 & 14,3 \\
Federal & 2 & 28,5 \\
Outros & 1 & 14,3 \\
Não respondeu & 2 & 28,5 \\
\hline Total & 7 & 100,0 \\
\hline
\end{tabular}

No presente estudo conseguiu-se observar que o grau de escolaridade dos cuidadores não superou o ensino superior incompleto $(n=1)$. Quatro cuidadores possuíam somente o ensino fundamental, sendo que 2 destes não chegaram a concluí-lo, e apenas um possuía o ensino médio completo. No estudo também se identificou, através do questionário, que todos os cuidadores já perderam um ou mais dentes devido a lesão cariosa, ou doença periodontal.

No estudo, menos da metade dos pacientes com PC apresentava hábitos nocivos como respiração bucal, mordida hipertônica, consumo de doces, alimentação muito pastosa. O número de refeições para o paciente com PC variou, mas em todas as famílias foram observados que eram realizadas ao menos 4 refeições por dia ao paciente com PC (tabela 3).

Tabela 3. Distribuição percentual da presença de hábitos nocivos e número de refeições/dia, de acordo com as informações do cuidador, Presidente Prudente - 2017

\begin{tabular}{lll}
\hline Variável & $\mathbf{N}$ & $\%$ \\
\hline Hábitos Nocivos & & \\
Sim & 3 & 42,8 \\
Não & 4 & 57,2 \\
Total & 7 & 100,0 \\
No Refeições/Dia & & \\
Até 4 & 4 & 57,2 \\
De 5 a 8 & 2 & 28,5 \\
Não respondeu & 1 & 14,3 \\
\hline Total & 7 & 100,0 \\
\hline
\end{tabular}

No estudo podemos observar que a maioria dos cuidadores realizavam higiene bucal nos pacientes com PC, sendo que somente um não a realizava devido a agressividade do paciente (tabela 4), e para este, no exame clínico, foi constatado grande perda dos dentes. O método de higienização utilizado pelos cuidadores, em sua grande foi o mecânico utilizando creme dental associado com a escova, sendo que alguns deles, associavam junto a esse método os enxaguantes bucais comerciais. Apenas um não informou o método de higienização do paciente. 
Tabela 4. Distribuição percentual da presença de higiene oral do paciente com PC e seus respectivos métodos de higiene, de acordo com as informações do cuidador, Presidente Prudente $-2017$.

\begin{tabular}{lll}
\hline Variável & N & $\%$ \\
\hline Higiene Oral do Paciente & & \\
Sim & 6 & 85,8 \\
Não & 1 & 14,2 \\
Total & 7 & 100,0 \\
Método de Higiene & & \\
Pasta dental + Escova & 3 & 42,9 \\
Pasta+Escova+Enxaguante & 3 & 42,9 \\
Outros & 1 & 14,2 \\
\hline Total & 7 & 100,0 \\
\hline
\end{tabular}

Em relação ao CPOD observou-se que a média geral do índice na primeira abordagem foi de 15,2 e na segunda abordagem foi de 15,6 sendo constatado uma mudança no componente restaurado, uma vez que dentes do componente cariado presentes na primeira abordagem passaram para o componente de dentes restaurados na segunda abordagem. Isso deveu-se a intervenção clínica foi realizada com os pacientes, melhorando de certa forma, o quadro de saúde bucal. A média de dentes cariados foi de 3,7 na primeira avaliação e de 1,7 na segunda. Já entre os dentes perdidos, a média foi de 5 e 5,2 no primeiro e segundo exame, respectivamente. Por fim, o componente restaurado teve valor médio de 6,5 e 8,7, respectivamente.

Em relação ao IHOS, durante a primeira e segunda avaliação observou-se melhora nos índices, sendo possível verificar que os pacientes com IHOS bom mantiveram esta classificação, e o regulares se transformaram em bons, tendo sido classificado apenas 1 voluntário com fraco controle de biofilme, no grupo que já possuía elevada perda dentária, foi relatado pelo cuidador que este paciente possui comportamento agressivo durante a higienização (Tabela 5).

Tabela 5. Distribuição percentual da classificação do IHOS nos pacientes com PC, na primeira e na segunda abordagem, Presidente Prudente - 2017

\begin{tabular}{lllllll}
\hline IHOS & 1a Abordagem & $\mathbf{N}$ & $\mathbf{\%}$ & 2a Abordagem & $\mathbf{N}$ & \% \\
\hline & Bom & 3 & 42,9 & Bom & 6 & 85,8 \\
& Regular & 3 & 42,9 & Regular & 0 & 0,0 \\
& Fraco & 1 & 14,2 & Fraco & 1 & 14,2 \\
\hline Total & & 7 & 100,0 & & 7 & 100,0 \\
\hline
\end{tabular}

Apesar de sugestiva melhora no índice IHOS, a comparação deste nos dois períodos avaliados, não apresentou significância estatística $(p=0,1003)$, sugerindo efetividade na orientação dos cuidadores.

\section{DISCUSSÃO}

O estudo em questão avaliou os pacientes com PC das mais variadas idades. Devido ao pequeno número de pacientes voluntários para a pesquisa, não foi possível determinar uma faixa etária especifica, sendo todos os pacientes avaliados da mesma forma. Um dos primeiros aspectos que foi observado é que todos os cuidadores dos pacientes com PC no estudo eram do gênero feminino, a maioria delas mães e apenas uma madrasta, mas com o mesmo papel maternal. Tal fato é de extrema importância, pois com o passar dos anos a mulher vem exercendo um papel fundamental nos cuidados e na atenção da saúde na família, principalmente na saúde bucal. Segundo Domingues et al $(2008)^{21}$, a mãe no ambiente familiar atua como importante figura 
devido ao fato de ser a principal personagem da família com voz em suas decisões, em especial em questões relativas ao binômio saúde-doença. Com isso, o seu papel pode influenciar positivamente ou negativamente as ações de promoção de saúde bucal, sendo decisivo para uma boa ou má higiene bucal dos indivíduos sob os quais é responsável, e por extensão, toda a família ${ }^{21}$.

Foi possível observar que fatores múltiplos podem ser relacionados com a situação da condição de saúde bucal do paciente com PC, pois pode se observar no estudo que fatores como renda e escolaridade podem trazer pioras em sua cultura e nos cuidados que os responsáveis devem realizar nos pacientes com PC. A renda média de todas as famílias dos pacientes com PC no estudo não superou 2 salários mínimos, sendo este uma observação importante, visto que os custos para pacientes com necessidades especiais são mais elevados devido ao alto custo dos medicamentos, muitas vezes necessários para este público. Há ainda que se considerar o alto custo dos tratamentos adequados para este tipo de paciente, que exigem muitas vezes uma equipe multidisciplinar capacitada. Segundo Silveira $(2010)^{22}$, a questão financeira é uma preocupação comum famílias de pacientes com necessidades especiais que necessitam de cuidados de saúde. Tal fato faz com que a família tenha uma limitação legítima de recursos gerando um ciclo de esgotamento emocional e físico. Ressalta ainda que devido à falta de recursos, a família muitas vezes não possui nenhum acesso a cuidadores devidamente treinados que possam realizar o cuidado técnico necessário para o paciente, tanto dentro quanto fora de casa, fazendo com que a família tenha dedicação integral nos cuidados deste paciente, limitando a sua vida social e profissional ${ }^{22}$. Um exemplo dessa questão citada acima no texto pode ser representado na escolaridade dos cuidadores dos pacientes com PC, dentre os quais, $57,1 \%$ possuíam apenas o ensino fundamental, o que pode estar relacionado com a dedicação integral nos cuidados do paciente com PC.

Observa-se no estudo que todos os cuidadores já perderam ao menos um dente devido a lesão cariosa ou doença periodontal, e essa condição muitas vezes é derivada de múltiplos fatores que contribuem para o decréscimo na saúde bucal, como fatores socioeconômicos, educacionais e ambientais. Segundo Barbato et al (2009) ${ }^{23}$ a piora no fator socioeconômico está associada com as perdas dentárias e foi relatada em outros estudos, independente da faixa etária, sendo que cárie e doença periodontal são as condições mais prevalentes, com maior extensão e gravidade dentre grupos menos favorecidos ${ }^{23}$.

Em relação aos hábitos nocivos, menos da metade os apresentou. Segundo Lemos et al. $(2012)^{10}$, quando a alimentação pastosa permanece por mais tempo na cavidade bucal, associada com a dificuldade em realização da higiene, levam ao maior acumulo de biofilme, e, portanto, torna-se fundamental considerar as características da dieta e dos hábitos nocivos durante o planejamento odontológico destes pacientes ${ }^{10}$.

Outro fator observado foi a higiene bucal do paciente, sendo que $85,8 \%$ realizavam-na. Um fator determinante para higiene bucal é a frequência e o tipo de higiene realizada. No estudo prevaleceram métodos tradicionais como a pasta e escova $(42,9 \%)$, ou até enxaguantes comerciais sem prescrição do profissional (42,9\%), e, foi relatado que muitas vezes, devido aos espasmos musculares, regiões posteriores do paciente e de difícil acesso ficavam sem a devida higienização. Segundo Carvalho et al. (2004) ${ }^{6}$ em alguns casos, a placa bacteriana pode ser controlada não apenas com métodos de escovação tradicionais, mas sim por meios químicos, utilizando substâncias antimicrobianas, e, segundo Lemos et al. $(2012)^{10}$ um programa de controle químico e mecânico do biofilme dental deve ser instituído previamente para prevenção da carie e doença periodontal ${ }^{6,10}$.

A melhora no índice CPOD pôde ser constatada no estudo, no qual houve acréscimo no componente restaurado e diminuição no componente cariado. Procedimentos como estes são necessários para que traga um melhor bem-estar geral no paciente com PC evitando problemas 
como a dor que podem não só interferir apenas no meio bucal mas afetar diretamente o seu bemestar geral, provocando incômodo ao paciente com a PC e ao seu cuidador. Segundo Camargo $(2004)^{24}$, o cirurgião dentista deve se esmerar na atuação com pacientes portadores de PC, realizando procedimentos restauradores que irão contribuir positivamente na reabilitação, visando proporcionar a eles adequada condição de saúde bucal ${ }^{24}$.

Outro aspecto relevante observado no estudo foi a redução no IHOS entre as duas abordagens, sugestivo de que a orientação realizada foi efetiva. Ao conscientizar os cuidadores na realização da higienize bucal do paciente, promove-se melhoria na saúde, pois devido ao controle de biofilme, problemas como gengivite, doença periodontal e cárie são mais facilmente evitados, aumentando assim seu bem-estar e sua condição bucal. Segundo Carvalho e et al $(2004)^{6}$ problemas como cárie e doença periodontal são derivadas de problemas de ordem geral e local, e podem se acentuar através do uso de medicação de rotina como psicoativos e anticonvulsivantes, podendo interferir na saúde. Dessa forma, o controle mecânico efetivo da placa bacteriana contribui para a melhora da saúde geral e bucal desses pacientes ${ }^{6}$. Mesmo com essas observações foi possível constatar que ocorrem problemas que fogem do âmbito deste estudo e, principalmente do consultório odontológico, como fatores psicológicos e limitações relacionadas diretamente ao cuidador que é responsável pelo paciente com PC. Segundo Silva et al. $(2005)^{5}$ quando lidamos com um paciente especial, lidamos também com seus familiares que muitas vezes possuem ansiedades, angústias e problemas. Sendo assim, precisamos estar cientes que a família que convive com um membro com limitações, possui mudanças drásticas no seu padrão de vida e na sua estrutura, ocorrendo uma mudança no funcionamento do próprio lar e, dessa forma, devemos esperar algumas atitudes dos pais relacionadas a rejeição ou até a superproteção ${ }^{5}$.

Apesar de pesquisa mostrar redução no IHOS entre as duas abordagens, na análise dos dados do IHOS não foi possível verificar uma significância estatística $(p=0,1003)$, o que pode deverse ao número limitado de pacientes. Segundo Oliveira et al. $(2004)^{25}$, os programas de promoção de saúde bucal voltados para pacientes com necessidades especiais demonstram redução no índice de placa bacteriana, doença periodontal e cárie, sugerindo que uma intervenção precoce, a qual inclui motivação e educação de seus responsáveis, é a forma de adquirir resultados positivos para o tratamento e manutenção da saúde bucal deste paciente ${ }^{25}$.

Mais estudos como este devem ser realizados visto que esse assunto necessita de uma maior atenção de toda comunidade odontológica visto que ainda é uma área escassa de estudos. Devido à falta de incentivo e políticas públicas que supram as necessidades destes pacientes, novos programas devem ser criados voltados para pacientes com PC, o que corrobora com o estudo de Queiroz et al (2014) ${ }^{26}$.

\section{CONCLUSÃO}

A melhora das condições de saúde bucal dos pacientes com PC sugere efetividade nas orientações realizadas, porém não foi observada diferença estatística significante.

\section{REFERÊNCIAS}

1. Tomita NE, Fagote BF. Programa Educativo em Saúde Bucal para Pacientes Especiais. Odontol e Soc. $1999 ; 1 / 2(1)$ : 45-50.

2. Mihi VM, Silvestre FJ, Orellana LM, Silvestre-Rangil J. Resting position of the head and malocclusion in a group of patients with cerebral palsy. J Clin Exp Dent. 2014; 6(1): e1-6, https://doi.org/10.4317/jced.51129.

3. Gorter JW, Ketelaar M, Rosenbaum P, Helders PJM, Palisano R. Use of the Gross Motor Function Classification System in infants with cerebral palsy: the need for reclassification at age 2 or older. 
Development Medicine \& Child Neurology. 2009; 51(1): 46-52, https://doi.org/10.1111/i.1469$\underline{8749.2008 .03117 . x}$

4. Cardoso AMR, Cavalcanti YW, Padilha WWN. Impacto de Programa de Promoção em Saúde Bucal para Cuidadores e Crianças com Paralisia Cerebral. Pesq Bras Odontoped Clin Integr. 2011; 11(2): 223-229, https://doi.org/10.4034/PBOCl.2011.112.12.

5. Silva ZCM, Pagnoncelli SD, Weber JBB, Fritscher AMG. Avaliação do Perfil dos Pacientes com Necessidades Especiais da Clínica de Odontopediatria da Faculdade de Odontologia da PUCRS. Rev Odonto Ciencia. 2005; 50(20): 313-318.

6. Carvalho EMC, Araujo RPC. A Saúde Bucal em Portadores de Transtornos Mentais e Comportamentais. Pesq Bras Odontoped Clin Integr. 2004;1(4): 65-75.

7. Ferreira AJ. Cartilha do Censo de 2010 de Pessoas com Deficiência. Brasília: Secretaria de Direitos Humanos da Presidência da República; 2012. 32p.

8. Castro AM, Marchesoti MGN, Oliveira FS, Novaes MSP. Avaliação do tratamento odontológico de pacientes com necessidades especiais sob anestesia geral. Rev Odontol Unesp. 2010;39(3): 137142.

9. Tessier DW, Hefner JL, Newmeyer A. Factors Related to Psychosocial Quality of Life for Children with Cerebral Palsy. Int J Pediatr.2014: 1-6, https://doi.org/10.1155/2014/204386

10. Lemos ACO, Katz CRT. Condições de saúde bucal e acesso ao tratamento odontológico de pacientes com paralisia cerebral atendidos em um centro de referência do Nordeste - Brasil. Revista CEFAC. 2012; 14(5): 861-871, https://doi.org/10.1590/S1516-18462012005000045.

11. Sehrawat N, Marwaha M, Bansal K, Chopra R. Cerebral Palsy: A Dental Update. Int J Clin Pediatr Dent. 2014; 7(2): 109-118, https://doi.org/10.5005/jp-journals-10005-1247.

12. Neves ET, Cabral IE. A fragilidade e a vulnerabilidade social das crianças com necessidades especiais de saúde. Rev Gaucha Enferm. 2008; 29(2): 182-90.

13. Santos PSS, Mello WR, Wakin RCS, Paschoal MAG. Uso de Solução Bucal com Sistema Enzimático em Pacientes Totalmente Dependentes de Cuidados em Unidade de Terapia Intensiva. Rev Bras Ter Intensiva. 2008 Jun; 20(2): 154-159, https://doi.org/10.1590/S0103507X2008000200007.

14. Costa FS, Neves LB, Bonow MLM, Azevedo MS, Schardosim LR. Efetividade de uma estratégia educacional em Saúde Bucal aplicada a crianças deficientes visuais. RFO. 2012; 17(1): 12-17.

15. Camargo MAFC, Frias AC, Antunes JLFA. The incidence of dental caries in children and adolescents who have cerebral palsy and are participating in a dental program in Brazil. Spec Care Dentist. 2011; 31(6): 210-215, https://doi.org/10.1111/j.1754-4505.2011.00213.x.

16. Thiollent M. Metodologia da pesquisa ação. 15 ed. São Paulo: 2007. 
17. Tripp D. Pesquisa-Ação: Uma introdução Metodológica. Educação e Pesquisa, São Paulo. 2005; 31(3): 443-466, https://doi.org/10.1590/S1517-97022005000300009.

18. Prado JS, Aquino DR, Cortelli JR, Cortelli SC. Condição Dentaria e Hábitos de Higiene Bucal em Crianças com Idade Escolar. Revista Biociência. Taubaté. 2001; 7(1): 63-69.

19. Cypriano S, Sousa MLR, Wada RS. Avaliação de índice CPOD simplificados em levantamentos epidemiológicos de carie dentaria. Rev Saude Publica. 2005; 39(2): 285-92, https://doi.org/10.1590/S0034-89102005000200021

20. Gomes VE, Silva DD. A importância do controle de placa dental na clínica odontológica. Arq Odontol. 2010; 46(01): 22-27.

21. Domingues SM, Carvalho ACD, Narvai PC. Saúde bucal e cuidado odontológico: Representações sociais de mães usuárias de um serviço público de saúde. Rev Bras Crescimento Desenvol Hum. 2008; 18(1): 66- 78, https://doi.org/10.7322/ihgd.19867.

22. Silveira AO. Definindo o projeto de vida familiar: A família na transição para o cuidado domiciliar da criança com necessidades especiais [tese]. Universidade de São Paulo. São Paulo, 2010.

23. Barbato PR, Peres MA. Perdas dentarias em adolescentes brasileiros e fatores associados: estudo de base populacional. Rev Saude Publica. 2009; 43(1): 13-25, https://doi.org/10.1590/S0034-89102009000100003.

24 Camargo MAF. Estudo da prevalência de carie em pacientes portadores de paralisia cerebral [dissertação]. Universidade de São Paulo. São Paulo, 2005, https://doi.org/10.11606/D.23.2005.tde-12012006-094913

25. Oliveira ALBM, Giro EMA. Importância da abordagem precoce no tratamento odontológico de pacientes com necessidades especiais. Rev Odontol Unesp. 2011; 19(38): 45-51, https://doi.org/10.15603/2176-1000/odonto.v19n38p45-51.

26. Queiroz FS, Rodrigues MMLF, Cordeiro Junior GA, Oliveira AB, Oliveira JD, Almeida ER. Avaliação das condições de saúde bucal de portadores de necessidades especiais. Rev Odontol Unesp. 2014; 43(6): 396-401, https://doi.org/10.1590/1807-2577.1013. 